\title{
An Interactive Intelligent Search Engine Model Re- search Based on User Information Preference
}

\author{
Dan Meng ${ }^{1}$, Xu Huang ${ }^{2}$ \\ ${ }^{1}$ School of Economics Information Engineering, mengd t@@swufe.edu.cn, dmengswufe@gmail.com \\ ${ }^{2}$ School of Business and Administration, hxu705@gmail.com \\ ${ }^{1,2}$ Southwest University of Finance and Economics, Chengdu, Sichuan, China, 610074
}

\begin{abstract}
Web service is very important for both e-commerce and e-government. However, web service process based on syntax level cannot deal with some user query very effectively. In order to make user get more information on the internet, semantic web is presented and many related research results have been given. By using semantic web, e-service has made a great progress to date. It makes the e-commerce and egovernment more flexible and effective than before. However, there are still a lot of problems related to semantic web need to be solved. One of these problems is that different user may have different information preference, i.e. they may care for and expect different information search results, which are closely related to their own special fields when different user input the same search key word. How to provide effective information retrieval results and provide individual user information retrieval service is an important research branch in the web service. In this paper, an intelligent interactive search engine model based on user information preference is discussed.
\end{abstract}

Keywords: Intelligent Search Engine, Artificial Intelligence, Personalization Search Service, User Information Preference

\section{Introduction}

With the rapid development and wide use of the Internet, more and more people and organizations are relying on information being given on the Internet. Search engine has played an important role when user try to search information on the Internet. However, information search has been brought the following problems: information excessiveness; information loss; information irrelevance because of the limitation of traditional search engine technology. In order to solve these problems, many researchers are focusing on research on intelligent search engine [5], [7], [8], [9], [16]. And some research results such as semantic web, semantic search, context search and synonymous search [1], [2],
[4], [6], [10], [11], [12], [14], [15] etc. have been given. Tim Berners-Lee stated that Web services are an actualization of the Semantic Web vision because the semantic markup of Web services makes them computer-interpretable, use-apparent, and agent-ready [3], [13]. These research results are important for realization of intelligent search engine.

However, present search engine has led to the following result, i.e., the search results will be the same if user input the same search key words by using a special search engine. In fact, different user has his own specific information requirement and information field. In order to provide individual information retrieval results for different user, search engine should learn user's information preference and give search results accordingly. There are some research results on individual search Engine [16]. In this paper, an interactive intelligent search engine model based on user preference is given.

This paper is organized as follows. In section 1, introduction will give a simple summary of research state and potential problems. In section 2, main part of user information preference database will be described. In section 3, model of intelligent interactive search engine based user preference will be given. In section 4, a simple conclusion will be given.

\section{User Information Preference Da- tabase}

Different users have different information preference. They may expect different information search results, which are closely related to their special field or need even if they input the same search key words. In addition, some of user's information search preference or search habit is regular. Therefore, it is feasible and very important for search engine to learn and know what kind of information is the user wants. Accordingly, user individual information database and user model database can be created and some machinelearning methods can be used to learn user information preference model. 
The following tables are main tables in user preference database.

Table 1. User Table

\begin{tabular}{|l|l|l|l|}
\hline Attribute & Type & Length & Primary Key \\
\hline User ID & Varchar & 20 & Yes \\
\hline User Password & Varchar & 20 & No \\
\hline
\end{tabular}

Table 2. User Information Preference Field Table

\begin{tabular}{|l|l|l|l|}
\hline Attribute & Type & Length & $\begin{array}{l}\text { Primary } \\
\text { Key }\end{array}$ \\
\hline No. & Integer & Default & Yes \\
\hline User ID & Varchar & 20 & No \\
\hline $\begin{array}{l}\text { Subjective Informa- } \\
\text { tion Preference Field }\end{array}$ & Varchar & 50 & No \\
\hline $\begin{array}{l}\text { Importance of Sub- } \\
\text { jective Information } \\
\text { Preference Field }\end{array}$ & Varchar & 50 & No \\
\hline
\end{tabular}

Table 3. User Information Preference Key Word Table

\begin{tabular}{|l|l|l|l|}
\hline Attribute & Type & Length & $\begin{array}{l}\text { Primary } \\
\text { Key }\end{array}$ \\
\hline No. & Integer & Default & Yes \\
\hline User ID & Varchar & 20 & No \\
\hline $\begin{array}{l}\text { Subjective Prefer- } \\
\text { ence Key word }\end{array}$ & Varchar & 50 & No \\
\hline $\begin{array}{l}\text { Position of Key } \\
\text { word }\end{array}$ & Varchar & 50 & No \\
\hline $\begin{array}{l}\text { Frequency of Key } \\
\text { Word }\end{array}$ & Varchar & 50 & No \\
\hline $\begin{array}{l}\text { Using time of Key } \\
\text { Word Varchar }\end{array}$ & 50 & No \\
\hline & Varchar & 50 & No \\
\hline
\end{tabular}

Note: By using table 2 and table 3, some of user information preference can be recorded and traced. Moreover, user information preference can be used to individuate user information search in intelligent search engine. Individual information preference character, including subjective information preference field and its importance, user preference model etc. can be formed by the following ways:

- User specify information preference field;

- Machine-learning:

$\circ$ Learn by position and frequency of key words;

- Feedback learning;

- Statistical learning.

\section{Model of Interactive Intelligent Search Engine}

In this section, a model of interactive intelligent search engine will be given.

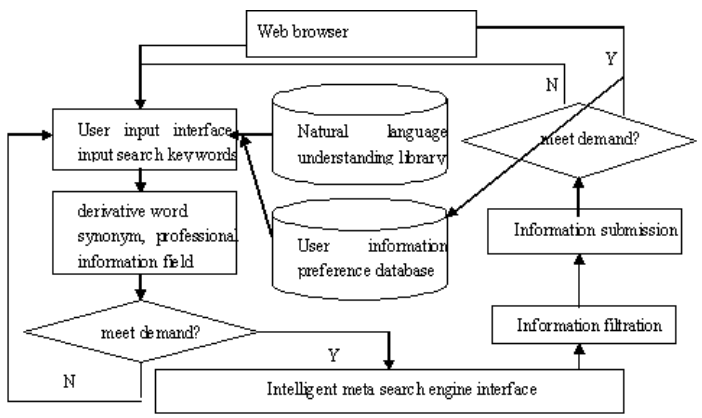

Fig. 1: Model of Real-time On-line Interactive Search Engine

The work principle of search engine is as follows:

(1) User identification and ask if the user want to edit information preference database;

If it is "YES", then do initialization; else go to (2) directly;

(2) User input search key word and its importance;

(3) Judge if the search key word is a new one, first do semantic search in user information preference database and using natural language library;

If it is actually a new one, then go to intelligent meta search engine and begin to search; otherwise, get derivative word, synonym and professional information field;

(4) User confirms if these derivative word, synonym and professional information field meet demands? If it is "YES", then begin to search by using these derivative word, synonym and professional information field as search key words;

If it is "NO", user input search key words, repeat this process until it meet user demand;

(5) Intelligent meta-search engine begin to search according to those key words and return retrieval result, then go to information filtration;

(6) Information submission, if the result meets user's requirement, then return to the web browser and at the same time, user information preference database learn the relevant user information model, including key word and its position and frequency, and record the corresponding time information.

In fact, different users have some special information field sometimes, so we can design an automatic information recommendation system, i.e., search engine can search information automatically according to user information preference, whether users are using the search engine to search information or not. As soon as the user opens the web browser, these related search results would be recommended to user directly and automatically. 
Here is a model of off-line automatic information recommendation system.

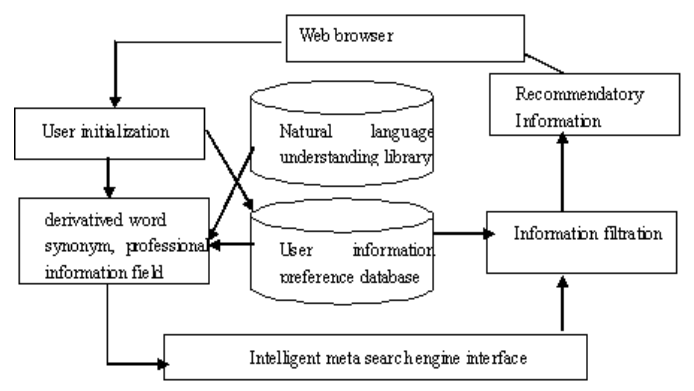

Fig. 2: Model of Off-line Automatic Information Recommendation System

The work principle of Model of Off-line Automatic Information Recommendation System is that combining user initialization, learned user information preference, which learns from user using process together with natural language understanding library to acquire derivable word synonym, professional information field.

\section{Conclusion}

In this paper, an interactive intelligent search engine model based on user information preference is given. It will be an effective and useful way to realize the individuation information search for different user information preference. Under this model framework, we can apply some artificial intelligent methods and technologies to improve the quality and effectiveness of information retrieval. In addition, this research result will be applied to e-commerce, e-bank, web advertisement, library information retrieval, goods sellers recommendation and other fields.

However, there are still some problems which need further detailed research. These problems include the following aspects:

(1) Search engine information presentation and organization;

(2) Effective and intelligent information retrieval mechanism;

(3) The theory foundation and approach on using machine-learning, artificial intelligent technology and method to acquire user information preference more effectively and accurately.

Further research work will be given in future research work.

\section{Acknowledgement}

This work was supported by the Scientific Research Fund of Southwestern University of Finance and Economics (Grant No. 06Q76) and the National Natural Science Fund of P.R.China (Grant No. 60474022).

\section{References}

[1] Berners-Lee, T., "Weaving the Web", San Francisco: Harper, 1999.

[2] Deng Wei, Zhang Zhiwei, Tan Qingping and Ning Hong, "A New Intelligent Search Engine", Computer engineering, Vol. 26, No. 3, pp. 8-10, 2000.

[3] E. Cerami, "Web Services Essentials", 1st edition (O'Reilly, CA, Sebastopol, Beijing, 2002.

[4] Fillies, Christian, Wood-Albrecht, Gay and Weichhardt, Frauke, “ Pragmatic Applications of the Semantic Web Using SemTalk", Computer Networks, 2003.

[5] Fu Xin, " Studies on Intelligent Trends in Third Generation Search Engines", Modern Library and information technology, Vol. 97, 28-30, 2002.

[6] "How to cut the cost of information distribution", Knowledge Management, 31, www.kmmag.co.uk, 2001.

[7] Hirokazu Watabe. and Tsukasa Kawaoka, "Automatic learning of Action Knowledge Base For a Mobile Robot Using Genetic Algorithms", Journal of Intelligent and Fuzzy systems, Vol. 15, pp. 219-223, 2004.

[8] "Intelligent Search Engine Developed", 7, New Media Age, 2004.

[9] Jos de Bruijn, Dieter Fensel, Uwe Keller, and Rubén Lara, "Using the Web Service Modeling Ontology to Enable Semantic e-business", Communications of the ACM, Vol. 48, No. 12, 43-48, 2005.

[10] Lei Li and Ian Horrocks, "A Software Framework for Matchmaking Based on Semantic Web Technology", International Journal of Electronic Commerce / Summer 2004, Vol. 8, No. 4, pp. 39-60, 2004.

[11] Roman, D. et al., "Web service modeling ontology", Applied Ontology Journal, 2005.

[12] Randy howard and Larry Kerschberg, "A framework for Dynamic Semantic Web Services Management", International Journal of Cooperative Information Systems, Vol. 13, No. 4, pp. 441-485, 2004.

[13] S. A. McIlraith, T. C. Son and H. Zeng, "Semantic web services", IEEE Intelligent Systems, vol. $16,2001$. 
[14] The Web's Father Expects a Grandchild, http://www.Business Week Online.

[15] Yoram Reich and Adi Kapeliuk and Frances Brazier, "Case-based Reasoning With Subjective Influence Knowledge", Applied Artificial Intelligence, Vol. 18, 735-760, 2004.

[16] Zhao Zhongmeng, Yuan Wei, He Shili and Shen Junyi, "Research on Intelligent Adjustive Algorithm for User Profile in Personalized Search

Engine", Computer Engineering and its application, Vol. 24, 184-187, 2005. 